\title{
Sustainability: Defining the New
}

\section{Paradigm}

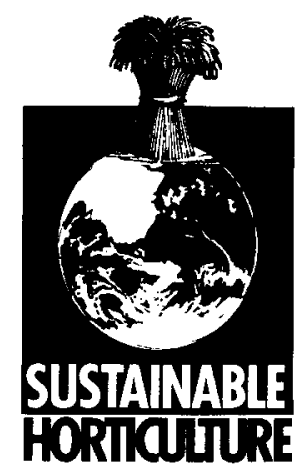

Thomas A. Fretz ${ }^{1}$, Dennis R. Keeney ${ }^{2}$, and Susan B. Sterrett ${ }^{3}$

"The land ethic simply enlarges the boundaries of the community to include soils, waters, plants, and animals or collectively: the land."

Aldo Leopold

The Land Ethic, 1949

\section{Introduction}

Conventional, chemical-based and energy-intensive agricultural systems are being scrutinized in the United States and throughout the world. The philosophy of fence row-to-fence row, high-input production systems of the late 1950s through the 1970s has given way to a rethinking among agriculturists and horticulturists that a decade ago was unimaginable. Today, agriculturists, policy analysts, and legislators are searching for an appropriate blend of technologies and policies that will lead to a more resourceefficient, environmentally sound agriculture that optimizes long-term profitability. This is a phenomena not limited to the United States; it is occurring throughout the world. Throughout this paper, while the principles and issues discussed are founded primarily on the our observations and interpretations of the U.S. system of agriculture, they are globally applicable. 
After the enactment of the Farm Bills of 1985 and 1990, many proponents of sustainable agriculture hoped that, by including sustainability among the stated goals of American farm policy, there would be an increased adoption of sustainable practices. An overview of the American farm scene reveals both optimism and pessimism. The optimism is founded in the fundamental changes in attitudes of farmers, policymakers, consumers, and scientists regarding sustainable agriculture and sustainable practices. Recent surveys (Lasley, 1989) conducted in Iowa reveal that farmers, in significant numbers, feel they are too dependent on farm chemicals and, to the extent possible, would like to reduce chemical inputs if suitable alternatives were available.

Conversely, conventional agriculture is so deeply embedded in American culture, its politics, and its institutions, that partisans are well-mobilized against the adoption of sustainable practices. Understanding the obvious production benefits of our traditional/ conventional farming practices forces one to query: What accounts for the growing interest among producers, policymakers, consumers, and scientists for these rediscovered sustainable practices? Why has sustainable agriculture moved so quickly to the public agenda for discussion, and even into the legislative arena?

Although the pace of attitudinal change has quickened, early efforts to achieve a greater movement toward sustainable agriculture have been slow. Many in the conventional agricultural establishment have openly opposed policy reforms aimed at creation of a more sustainable agriculture, particularly reforms aimed at efforts to reduce dependence on purchased inputs. Farm and commodity organizations, the media, and government agencies have not assessed accurately the magnitude of concern being raised in our evergrowing urban/suburban society to the issues of the food supply, food safety, environmental degradation, and the survival of rural communities. Valid concerns, however, have been raised by others (CAST, 1990) concerning the large-scale, long-term practicality of alternative or sustainable practices.

This rapidly emerging interest in sustainability has been summarized in recent studies (USDA, 1980; NRC, 1991). Concerns raised by farmers and other proponents of sustainability include:

- Increased cost and uncertain availability of energy and farm chemicals;

-Increased resistance of pests to chemical controls;

-Declining soil productivity due to erosion, accompanied by loss of organic matter and plant nutrients;
- Pollution of surface waters with agricultural chemicals and sediment;

- Depletion of finite reserves of concentrated plant nutrients (e.g., phosphate rock);

- Hazards to human and animal health from pesticides and feed additives;

- Destruction of wildlife, bees, and other beneficial insects by pesticides;

- Detrimental effects of agricultural chemi, cals on food quality;

- Decrease in the number of farms, particularly family farms.

Conventional agriculture involves highly specialized systems that emphasize high yields achieved with inputs of fertilizer, pesticides, and other off-farm purchases, as well as a variety of other high-input and often resource-depleting practices. This system has been remarkably effective in making U.S. agriculture the most productive in the world. The need to maintain a productive and efficient agricultural system is essential, but the development of management strategies that embrace the concepts of sustained soil productivity, reduced dependence on off-farm inputs, reduced environmental impacts, and improved economic stability is also essential. The issues of soil erosion, surface and ground water contamination, and food safety are of increasing importance to consumers and producers. Whether the issues are real or not, public perception of modern agriculture is deteriorating with the generally held beliefs that short-term benefits are being taken at the expense oflong-term consequences. Right or wrong, there is a growing public perception that food is unsafe, or at least has the potential for being unsafe, because of pesticide residues on food and/or in potable water. While the health risks to consumers from restricted-use pesticides may be far less than perceived, and far less significant than the health risks faced by farm families, the public is not convinced of the safety of their food and believe that something must be done.

As we approach the 21 st century, agriculturists will be faced with ever-increasing pressures to ensure that agricultural practices meet the test of sustainability. The long-term sustainability of agricultural systems, including systems for the production of horticultural crops, will concern diverse groups, with each placing different emphases on their concept of sustainability (Allen et al., 1991).

Two perspectives of sustainability are easily differentiated. Sustainability that is defined in terms of pressing social issues in the food and agricultural system vs. sustainability defined primarily in terms of resource conservation and profitability. Although sustainability needs to address both social and technical issues, more often than not strong emphasis has been placed on technical dimen-
"It is

inconceivable to

me that an

ethical relation to

land can exist

without love,

respect, and

admiration of

land, and a high

regard for its

value. By value, I

of course mean

something far

broader than

mere economic

value; I mean

value in a

philosophical

sense."

Aldo Leopold

The Land Ethic, 1949 
sions. The challenge for producers, scientists, administrators, and policymakers will be to address these issues, focusing on the development of technologies that ensure long-term sustainability and productivity.

\section{Definitions of sustainability}

'Land then, is not merely soil; it is a fountain of energy flowing through a circuit of soils, plants and animals."

Aldo Leopold The Land Ethic, 1949
As the concept of sustainability has evolved, so has the definition. Some consider sustainable agriculture to be a philosophy, while others view it as a set of guidelines for choosing practices-i.e., a management strategy (Harwood, 1990). Both views must be considered in any workable definition of sustainable agriculture. The concept of sustainable agriculture varies by individual, discipline, profession, and area of concern. The literature offers literally dozens of definitions, many being variations on a central theme; however, all incorporate many of the following characteristics: long-term maintenance of natural systems; adequate economic returns per unit of production; optimal production with lower or minimized inputs; satisfaction of human need for food and income; and provision for the social needs of farm families and communities (Keeney, 1990). By necessity, all definitions of sustainable agriculture promote environmental, economic, and social goals in an effort to interpret clearly the meaning of sustainability (NRC, 1991). Perhaps the term "sustainable agriculture" may be too desirable. Who would advocate the development of a "non-sustainable agriculture"?

Briefly stated, the National Research Council has defined sustainable agriculture as "a management system for the preservation of natural resources that provide food, income, and livelihood for present and future generations and concomitantly maintains or improves the economic productivity and ecosystem of these resources" (NRC, 1991). This definition requires that sustainable agricultural systems be both economically and ecologically viable. These sustainable systems must be resource-conserving, environmentally sound, socially responsible, and commercially competitive. Farming systems that fail to conserve their resource base will eventually lose their ability to produce. Systems that fail to protect the environment eventually will do more harm than good, and ultimately will destroy their reason for existence. Therefore, sustainable systems will be ecologically sustainable.

Any useful definition of agricultural sustainability must acknowledge social issues, as well as those of production, environment, and the economics of production and marketing; but it must also recognize the need for compromise between all of the highly interactive elements that compose agriculture.
Using these criteria, Allen et al. (1991) proposed the following definition of sustainable agriculture: "A sustainable agriculture is one that equitably balances concerns of environmental soundness, economic viability and social justice among all sectors of society."

This definition is consistent with that offered by Wittwer (1978) that called for a research agenda that would "develop new agricultural technologies to contribute to an economically, socially and ecologically sound agriculture." One might add as a footnote that Wittwer was ahead of his time and had in fact defined sustainable systems before it became a popular buzzword of the late 1980s. The process of defining a sustainable agriculture was outlined further by Rodale (1983) as " a system that would in the course of a food production system, improve the status quo of soils, rather than just maintain or even degrade them." Rodale termed this concept not sustainable agriculture, but "regenerative" agriculture (Rodale, 1985).

More recently, Francis et al. (1987) summarized a practical definition of sustainable agriculture that describes the production components or decisions that a producer is required to make each growing season. " $A$ sustainable agricultural system is the result of a management system which helps the producer to choose the hybrids and/or varieties, soil fertility packages including rotations, pest management approaches, tillage methods, and crop sequences to reduce costs of purchased inputs, minimizing the impact of the system on the immediate and the off-farm environment, and provide for a sustained level of production and profit from farming."

Bird (1988), in Congressional testimony, described sustainable agriculture as an optimization process that "uses quality of life mandates, atmospheric resources, organic reserves, sedimentary resources, external inputs, and material residues for the long-term sustainable production of appropriate amounts of reasonably priced food, feed and fiber, while maintaining a long-term high quality environment." Furthermore, he testified that sustainable agriculture is both knowledge-and management-intensive, and it must "provide long-term added value to the biological, environmental and human capital on which agriculture is based."

In 1989, the American Society of Agronomy, in defining sustainable agriculture as " $a$ sustainable agriculture is one that, over the long-term, enhances environmental quality and the resource base on which agriculture depends; provides for basic human food and fiber needs; is economically viable; and enhances the quality of life for farmers and society as a whole," embraced both the concept and a philosophy (ASA, 1989). 
Clearly, sustainable agriculture is a philosophy based on human goals and on better understanding of the long-term impacts of our activities on the environment and on other species. In the remainder of this decade, greater attention likely will be given to the development of this philosophy as it guides administrative and policymaking decisions to create truly integrated, resourceconserving, equitable farming systems. These systems will reduce environmental degradation, maintain agricultural productivity, promote economic viability, and maintain stable and viable rural communities and quality of life.

\section{K ey concepts to sustainability}

A sustainable agriculture must have a solid foundation on well-researched agronomic and horticultural practices and principles. Policy and practice must reflect scientific fact. Erosion control, effective and efficient weed management, maximum efficiency of on-farm and purchased inputs, reduction of nutrient leaching from the root zone, and an overall view toward utilization of sound biological principles (Keeney, 1989). Each of these factors play a role in establishing a more sustainable agriculture.

Soil erosion. To achieve a truly sustainable agriculture, maintenance of soil productivity must be achieved. Without question, whether it be for agronomic or horticultural crops, control of soil erosion has always proven to be difficult. The pursuit of a truly sustainable agriculture-practices used in our efforts to conserve and therefore reduce soil lossesmust be economical and, above all, must not involve tradeoffs that increase the rate of pollution. Ideally, any sustainable agricultural system must consider soil conservation as a primary component (Keeney, 1989).

Cultural practices. The unparalleled growth in output from both the American and global agricultural scene is due, in part, from the use of readily available and relatively inexpensive commercial fertilizers, particularly nitrogen fertilizers. Additionally, improved crop varieties with greater yield expectations and disease/pest resistance potential and improved pest and disease control through the development of synthetic organic pesticides over the last 40 to 50 years has been largely responsible for the world increases in agricultural productivity. Can we expect either U.S. or global agricultural productivity to continue to grow at the current unprecedented rates while maintaining and even enhancing a sustainable agricultural system? Are the current projections for a continued $2 \%$ per year increase in crop production realistic? These questions are critical to the debate over the need to increase food production to meet the unparalleled growth in population worldwide, coupled with the increased concern and emphasis on maintaining a sustainable agriculture.

Biological cycles are not "tight" in the ecological sense, particularly for nitrogen (Odum, 1989). It is recognized generally that horticultural crops remove large quantities of nutrients during their growth cycles. Although some soils have large natural reservoirs of potassium and phosphorus, and some have received abundant supplies of these nutrients from fertilizer, all cropped soils eventually run short of available potassium and phosphorus as they support crop production. When possible, this cycle can be delayed with the use of animal manures (no longer a widely used horticultural practice). Regardless of the cropping system, nutrients ultimately must be supplied from external sources ifeconomic yields are to be maintained (Hoeft and Nafziger, 1988; York, 1989).

Nitrogen management offers the greatest opportunity for achieving or enhancing sustainability through fostering the use of legumes and animal wastes-practices long neglected and overlooked in the production of horticultural crops. Management systems either are available or are being developed that greatly increase the efficiency of nitrogen use in row crops. In the future these management systems might include biotechnology to engineer genetically more-efficient legumes, nitrogen credits for manure and legumes, better handling of animal wastes, better and more-timely application of nitrogen at the time of-maximum crop use to avoid, or at least minimize, losses while minimizing excess nitrate in the root zone (Keeney, 1986). Ultimately, environmentally and productively sound decision information systems will be available to assist in management decisions.

Crop rotations. Crop rotations, as opposed to monocultures, are considered a critical component of soil- and resource-conserving agricultural systems. Legumes, and particularly alfalfa, although seldom considered in production of annual horticultural crops, should be used to a greater extent as the primary alternative crop in a cropping sequence. Legumes have well-recognized benefits, including reduction of soil erosion and increasing soil tilth, in addition to nitrogen fixation (NRC, 1989). Normally, profitability from the use of legumes in the farming system requires the incorporation of ruminant animals in the system. For the producer of horticultural crops, alternative solutions might be the development ofadditional markets for the harvested legume, while still benefiting from the soil- and nitrogen-building effects.
“. . a system of

conservation

based solely on

economic self-

interest is

hopelessly lop-

sided. It tends to

ignore, and thus

eventually to

eliminate, many

elements in the

land community

that lack

commercial

value, but that

are (as far as we

know) essential to

its healthy

functioning."

Aldo Leopold

The Land Ethic, 1949 
"We abuse land

because we

regard it as a

commodity

belonging to us.

When we see Lund

us a community

to which we

belong, we may

begin to use it

with love and

respect. . . That

land is a

community is the

basic concept of

ecology, but land

is to be loved and

respected is an

extension of

ethics."

Aldo Leopold

Preface to The Land

Ethic, 1949
Chemical inputs (pesticides). The issue of pesticide use on crops consumed directly by the public, as is the case with many of our horticultural crops, or on crops used principally for processing or animal feed is in reality two distinct and different issues. The first question pertains directly to the issue of food safety and quality, while the second issue is related to environmental, social, and economic concerns. Most farming systems involving intensively managed crops require the addition of some pesticides. Replacement of these inputs with management techniques, including modified tillage systems, cultivation, and crop rotational sequences will require long-term research and experimentation, and success will be only achieved slowly.

Another development will be the rapid development of genetically engineered pestresistant crops, allowing for reduced synthetic inputs, and engineered crops resistant to broad-spectrum herbicides such a glyphosate. These "herbicide-seed" packages, as they might be termed in the future, are nearing the final stages of development and are nearly ready for testing in agronomic crops. Horticultural crops are likely not far behind. These herbicide-seed packages offer the potential for greatly extending the current herbicide era, and their use will likely bring to the forefront a number of ethical issues ofconcern to those who are attempting to achieve a more sustainable agriculture.

Role of new technologies. Erroneously, many people are quick to equate sustainability with a return to "old-time" farming practices; however, this view is not valid. One can never return to old technologies. Rather, new technologies will be required to help achieve sustainability. In case studies cited in the NRC report (NRC, 1989), the major deviations from conventional practice includes the substitution of labor and land for pesticides and the dependence on specialized markets for profitability (Black, 1990). For largescale, long-term sustainability, new technologies must be developed. These new technologies will range from the simple to the complex and will come from all industrial and technological segments, including the equipment, electronics industries, the agrichemical supply and consulting sector, and the private seed and biotechnology industries. Only time will tell how each of these technologies will affect our ability to maintain and enhance the sustainability of our agriculture. It will, however, be critical that adequate and expanding research be supported to assure that these new technologies are incorporated into the resource-conserving agricultural system of the future (Francis, 1991).

As we review and compare the impacts of our conventional agricultural system and sys- tems that might lead to a more sustainable agriculture, we will likely need to answer numerous questions and alleviate concerns of the public.

-What contributions can the conversion toward a more sustainable agriculture make toward nonrenewable energy and water resources?

- How can current sustainable practices be made even more energy-efficient?

-What market mechanisms can be created to reward stewardship (and, conversely, penalize practices that result in environmental degradation)?

-Given the reality of reduced federal farm spending (subsidies), how can the transformation to more sustainable practices and systems be financed?

- How can we sustain food production in the face of potential global warming?

-How can the principles of optimization of resource input rather than maximization be advanced?

\section{Challenges for the future}

A very complex puzzle, perhaps best stated as a dilemma-how to sustain food production into the future-now faces present and future agricultural/horticultural scientists. The global challenge is to use our knowledge to confront the dilemma of how to intensify an agriculture with a diminishing fossil fuel resource base, how to feed an everexpanding human population, and still protect our environment. Achieving these goals will require rethinking our role in agricultural development. A philosophy of food production and development is emerging that depends on intensive and efficient use of renewable resources, elevates information and management as substitutes for nonrenewable energy-based resources, and allows for a balance with nature that provides for a good quality of life for humans and the survival of most other species (Francis, 1990b). To achieve a truly sustainable agriculture, including horticulture, a number of philosophic changes are required in our problem-solving approaches to feeding the world.

Expansion of interdisciplinary research. Despite evidence that there is growing involvement by scientists in interdisciplinary research, task forces, teams, and integrated centers, most scientists still dedicate the greatest portion of their time to narrow subject-matter areas. Unfortunately, many agricultural scientists have been unwilling, poorly prepared, without sufficient funds, or lacking in the confidence to deal with the larger, complex questions related to sustainable systems. Interdisciplinary research efforts must be encouraged to meet these chal- 
lenges. Efforts to enlist the cooperation of environmentalists, agrichemical industry scientists, and administrators to address the various components of the system and to find new and creative ways to finance these efforts in sustainable systems will be the challenge.

Explore innovative farming systems. Although the production of horticultural crops may be more finely tuned than the monoculture systems used with traditional agronomic crops (continuous corn, as an example), horticulturists fall victim to some of the same traps. Horticultural scientists need to continue to explore farming systems that are productive, yet sustainable. Combining improved rotations, legumes in the cover crop sequence, and improved nitrogen management will result in increased sustainability, through the use of renewable resources.

Change from a "product-use" to a "problem-solving" mentality. A productuse mentality has evolved as we rely on technology to solve problems in agriculture. When a grower has a weed problem in a field, the first question any extension specialist is likely to hear is, "What herbicide do I use to kill the weed"? A more-logical, process-orientated approach would be for the farmer and extension specialist to study the kinds of weeds present, their size (relative to stage of development), their frequency in the field, and then evaluate a number of management options. The use of a herbicide is just one of the options available.

To follow this "process-orientation" further, it is important to determine the characteristics of the system that has allowed the weed to become a problem. The goal in the "problem-solving" process mentality is to substitute information or management for a purchased input, thus reducing production costs and the potential for environmental contamination (Francis, 1991).

Accept responsibility for broader issues. Most scientists view their role as contributing basic knowledge in a specific discipline. Is it possible for agricultural scientists to break this pattern of thought and become involved in the broader, long-range issues facing us? The very first step is to recognize that larger issues do exist and that they are solvable.

Extend the time frame for solution of broader problems. Today we think in terms of planning research over relatively short periods of time. Research aimed at enhancing sustainability must be planned toward a time when results will be available to integrate into production systems. Because much of our field production research requires at minimum 3 to 5 years of field results, and plant improvement through breeding may take 10 to 15 years, it is crucial that we anticipate what the primary systems will look like a decade or later. How will these new component technologies fit together? Is it possible to anticipate the resource constraints along with potential economic and environmental incentives that will prevail after the year 2000, and to develop new, more-appropriate technologies? The challenge should be to design the future!

Adopt to the reality of finite fossil fuels. Most of our agricultural research continues to pursue technologies that depend on fossil fuels. While one cannot argue very effectively against a strategy that has been highly successful ... increasing productivity per unit of land, per human, and per unit of labor invested .... it goes without saying that these fuels will diminish in the future. As population continues to increase and resources become limited, it is time to respond to the greater challenge. How will we live within this constraint, and design food production systems that can deliver our needs and yet be sustainable for future generations?

The strategy that evolves will maximize efficient use of renewable resources-soil nutrients in organic and mineral fractions, rainfall, solar energy, wind, biomass, thermalwhile using fossil fuels only when absolutely necessary. This strategy will help preserve nonrenewable energy resources for future uses.

\section{The role of the land-grant university}

Given the many concerns, along with a public perception that the present American farm productivity scheme is not truly sustainable with current practices and policies, what role should we as agriculturists/horticulturists play in redefining of our mission in the land-grant university? First and foremost, land-grant universities and the cooperative extension system must take visible and bold leadership on the issues. Forward-thinking programs that combine land stewardship with socially viable and profitable farming systems must become fundamental to our thinking.

Central to any discussion on sustainability is the need to increase public funding of research, education, and technology transfer. It is indisputable that the land-grant university system will serve as a key agent in implementing any change that will accelerate the move to a more sustainable agriculture in the United States.

The passage by the U.S. Congress of the 1985 and 1990 Farm Bills authorized a new sustainable agricultural education program and increased funding for low-input sustainable agriculture (LISA). These bills, however, went far beyond authorization of indi-
"Forwardthinking programs that combine land stewardship with socially viable and profitable farming systems must become fundamental to our thinking." 
"As scientists

and extension

professionals lead

this move to a

more sustainable

agriculture, it

will become

evident that it

will be an

information-

rich, rather than

a strictly

technology-based,

form of

agriculture." vidual programs, and included directives to move the entire federally funded research program in directions generally more supportive of sustainability. The bill introduced several new criteria, including improved environmental quality and enhancement of rural communities, as fundamental objectives of agricultural research. Additionally, Congress directed the USDA to make its research programs conform, including changes in the National Research Initiative (NRI) competitive grants program, to emphasize research consistent with sustainable agricultural practices. As a result, fundamental questions lie before us as horticulturists and agriculturists that will need our attention in the remaining years of this decade and beyond. We can be assured of even greater emphasis being focused on sustainable agriculture in the next farm bill. Will we to be prepared to face the issues?

As we look to the land-grant university as a resource for research, education, and technology transfer, there continues to be considerable debate over the role of education and voluntary change as contrasted to using economics and regulation as the agents of change. If the route of education and voluntary change is preferable, it will require the active participation of the land-grant system. Our land-grant institutions have been the cornerstone of agricultural technology development that has enabled the United States to achieve its highly effective and efficient agricultural sector. Some suggest that these traditional paradigms of the land-grant institutions have been lost, or at least mislaid. As scientists and extension professionals lead this move to a more sustainable agriculture, it will become evident that it will be an information-rich, rather than a strictly technologybased, form of agriculture. Thus, the landgrant system should be well-poised to the task of providing answers to the questions that will be raised (Francis et al., 1990a). The questions are numerous, and the land-grant system will be asked to respond to the new challenges before us.

- Land-grant universities must recognize the need to target programs in agricultural sustainability for high-priority funding (including a commitment of up to $20 \%$ to $25 \%$ of the annual appropriated funds to this purpose).

- The land-grant university system must ensure that programs in sustainable agriculture become even more focused on national research and extension issues. This will require that the land-grant universities lead the effort to establish sustainable agriculture as a principal national agricultural priority.

- Understanding of sustainable agricultural issues by both research and extension professionals must be enhanced greatly through the development of training programs that are national in scope, but recognize the regional uniqueness of sustainable agricultural systems.

- The land-grant system of research, instruction, and technology transfer must support an expanded, long-term, science-based program to foster greater on-farm research and technology transfer aimed at meeting the goals of a more sustainable agriculture.

- To effectively influence agricultural research at our land-grant universities, sustainable agriculture proponents will need representation on advisory and decisionmaking boards and bodies to provide guidance and insight that will influence research direction.

- Emphasis will need to be placed on more fully incorporating on-farm research into the mainstream of agricultural research (Gerber, 1992).

- Agricultural scientists will need to incorporate technology assessment efforts into their research agendas that will allow an evaluation of social issues on an equal basis as the technical questions.

- Land-grant universities will need to include the public in efforts set the agricultural research agenda. This will require even closer working relationships among scientists, educators, consumers, and farmers (Gerber, 1992).

- Land-grant universities need to be involved in defining the most-urgent and pressing agricultural issues and working to see that they are incorporated into the national agenda.

- Efforts need to be made to develop and deliver research-based educational programming that will address and demonstrate the linkage between the economic and environmental issues associated with the individual practices as well as the total system of sustainable agriculture.

- The land-grant universities, the USDA, and state governments must work toward a national farm policy that focuses on long-term agricultural sustainability rather that shortterm benefits and returns.

- With leadership from the cooperative extension system, we must develop programs to assist farmers in improving their management skills and acquiring the information and knowledge necessary to farm in a sustainable fashion.

- Efforts must be established in cooperation with farmers to identify major information voids that restrict the development and acceptance of sustainable agricultural systems. Research and educational programs must be developed to fill these data gaps. 
- Land-grant universities must increase joint, multidisciplinary programs by both research and extension scientists in developing production practices and farming systems that reduce the use, or improve the efficiency, of nutrients and pesticides that result in a more sustainable agriculture.

- Land-grant universities must listen to all segments of the agricultural community. They need to be sensitive to and meet the needs of small farmers who cannot afford high-tech management and expensive consultants.

- Land-grant universities must be committed to the broad-based education of students, without the loss of scientific rigor, and must place some degree of emphasis on ecological principles and environmental ethics.

How we ultimately reach a level of sustainability in our agricultural systems will obviously not come from simple solutions to complex issues. In reality, it is a question of developing multiple objectives and pursuing these objectives with multiple strategies. By the very nature of the issues, this is a difficult challenge for government, university, and agricultural experiment stations to address. Maintaining and increasing agricultural sustainability into the next century will require us as horticulturists and agriculturists to incorporate the new environmental concerns into our concepts of sustainability and to communicate directly with the public.

As we imply here, there has been criticism of both the land-grant university system of research and education and the federal research establishment as being parts of the problem, rather than the solution. An analysis of the current research programs at major U.S. agricultural research and educational institutions reveals programs largely oriented toward intensive, high-energy farming, with an emphasis, either knowingly or not, on reducing farm labor requirements. In the end, very few research programs look seriously at the farming system. The traditional emphasis on reductionist research continues to be a deterrent to additional efforts in sustainable agriculture.

The key to achieving agricultural sustainability lies with the general public and in their ability to have impacts on the landgrant system of research, technology transfer, and education and the federal research establishment. We must understand that sustainable practices cannot be evaluated in the marketplace, and that they will very likely increase food prices. Agricultural policies that enhance sustainability will come from the public, not from the private/corporate sector. If achieved through a research approach, these new policies will be based on research and demonstration of farming systems that will provide new opportunities for farmers to do things right and still maintain an acceptable lifestyle.

To truly address research and educational issues in sustainable agriculture, leaders will need to redirect the education, technology transfer, and research infrastructure to encourage expansion of systems research that includes sociology and resource economics. Without the incorporation of these disciplines into the equation, it is highly unlikely that traditional agricultural scientists will be able to provide the answers to the complex questions being put forward. This effort must ensure adequate long-term funding as well as individual and collective rewards for systems research. New programs will emerge within the federal research establishment and the land-grant university system of research, technology transfer, and education that will lay the groundwork for a new approach to farming. These new programs will also accelerate the actual use of participatory research methods and encourage the development of alternative technologies and crops that reduce agriculture's dependence on energy-intensive purchased inputs.

Will these changes come in time? Who will lead the effort? It is apparent that this leadership has to come from a shared vision of the future and the acceptance of true integration of the land ethic into the public consciousness. There is no doubt that the leaderperhaps the major leader-in this effort will be the publicly supported agricultural research and education institutions-i.e., the Land-grant Universities and their associated Agricultural Experiment Stations and Cooperative State Extension Systems,

Are we ready for the challenge? Only time will tell!

\section{Literature Cited}

Allen, P., D. Van Dusen, J. Lundy, and S. Gliessman. 1991. Integrating social, environmental and economic issues in sustainable agriculture. Amer. J. Alt. Agr. 6:34-30.

American Society of Agronomy. 1989. Decisions reached on sustainable agriculture. Agron. News. Jan. p.15.

Bird, G. W. 1988. Sustainable agriculture: Current state and future trajectory. Congressional testimony on sustainable agriculture. Apr. 18, 1988. Washington, D.C.

Black, C.A. 1990. The Alternative agriculture report. Alternative agriculture scientists' review. Pg. 68-78. CAST, Ames, Iowa. CAST Spec. Publ.. 16:68-78.

CAST. 1990. Alternative agriculture scientists' review. CAST, Ames, Iowa. Spec. Publ. 16.

Francis, C.A., D. Sander, and A. Martin. 1987.
"To truly address research and educational issues in sustainable agriculture, leaders will need to redirect the education, technology transfer, and research infrastructure to encourage expansion of systems research

that includes sociology and

resource

economics." 
Search for a sustainable agriculture. Crops \& Soils (Aug.-Sept.):12-14.

Francis, C., J. King, J. DeWitt, J. Bushnell, and L. Lucas. 1990a. Participatory strategies for information exchange. Amer. J. Alt. Agr. 5:153-160.

Francis, C.A. and G. Youngberg. 1990b. Sustainable agriculture: An overview, p. 1-23 In: C.A. Francis, C.B. Flora, and L.D. King (eds.). Sustainable agriculture in temperate zones. Wiley, New York.

Francis, C. 1991. Sustaining agriculture and development: Challenges for the future. Amer. J. Alt. Agr. 4:98-99, 192.

Gerber; J.M. 1992. Participatory research and education: Science in service to horticultural producers. HortTechnology 2(1):12-15.

Harwood, R.R. 1990. A history of sustainable agriculture, p. 3-9. In: C.A. Edwards, R. Lai, P. Madden, R.H. Miller, and G. House (eds). Sustainable agricultural systems. Soil and Water Conservation Soc. Ankeny, Iowa.

Hoeft, R.G. and E.D. Nafziger. 1988. Sustainable agriculture. Better Crops 72(2):9-11.

Keeney, D.R. 1986. Sources of nitrate to ground water. CRC Crit. Rev. in Environ. Control. 16(3):257-304.
Keeney, D.R. 1989. Toward a sustainable agriculture: Need for clarification of concepts and terminology. Amer. J. Alt. Agr. 4:101-105.

Keeney, D.R. 1990. Sustainable agriculture: Definition and concepts. J. Prod. Agr. 3:281-285.

Lasley, P. 1989. Iowa farm and rural life poll1989 summary. Iowa Coop. Ext. Serv. Pm 1369.

National Research Council. 1989. Alternative Agriculture. National Academy Press, Washington, D.C.

National Research Council. 1991. Toward sustainability: Soil and water research priorities for developing countries. National Academy Press, Washington, D.C.

Odum, E.P. 1989. Input management of production systems. Science 243:177-182.

Rodale, R. 1983. Breaking new ground: The search for sustainable agriculture. The Futurist 17(1):1520 .

USDA. 1980. Report and recommendations on organic farming. U.S. Government Printing Office. Washington, D.C.

Wittwer, S.H. 1978. The next generation of agricultural research. Science 199(4237):375.

York, E.T. 1989. Research for a sustainable agriculture. Better Crops 73(3):8-11 